\title{
Vector Control-Development and Improvement of the Modern Chemical Insecticides
}

Ivan Popivanov ${ }^{1}$, Tanya Petkova ${ }^{2}$, Victoria Doycheva ${ }^{3}$, Tzetza Doychinova ${ }^{2}$, Ivelin Angelov $^{2}$ and Dimitar Shalamanov $^{2}$

1. Department of Military Medicine, Military Medical Academy, Sofia 1606, Bulgaria

2. Department of Infectious diseases, Epidemiology, Parasitology and Tropical Medicine, Medical University, Pleven 5800, Bulgaria

3. Department of Epidemiology, Medical University, Sofia 1431, Bulgaria

\begin{abstract}
The transition from empirical and applied approach toward a scientific approach in modern medical disinsection is a result of the discoveries of the organic chemistry. The most intensive used substance in this field-DDT (dichlorodiphenyltrichloroethane) is introduced during World War II and contributes to world practical epidemiology just as antibiotics in clinical medicine. However, after the 70s, this substance was placed under a ban, because of the accumulated evidence of many adverse health and environmental impacts globally. Improvement of the insecticides after "DDT-era" is represented by the introduction of organophosphate and carbamate insecticides in the 1960s. Their broad application is determined by better ecotoxicological characteristics. The advance in biotechnology after the 1980s establishes the new class of insecticides—synthetic pyrethroids. Nowadays they are basic for the insect control. Pyrethroids are characterized by selective impact on insects with much less impact on warm-blooded animals and the environment. Insecticides from the newest class insect growth regulators realize their mode of activity by interfering with chitin metabolism and thus prevent an insect from reaching maturity. These substances have extremely low toxicity, which makes them very promising for the treatment of civilian and military facilities.
\end{abstract}

Key words: Vector control, insecticides, development.

\section{Introduction}

The endemic nature of a part of the infectious diseases is associated with mandatory involvement of live vectors in the epidemiological chain. General assumptions about this date back to ancient times, but the first reasoned link between insects and disease was made in 1717 by Lancisi, a court physician to Popes Innocent XI, Clement XI and Innocent XII. In his work "De noxiis paludum effluviis eorumque remediis il (On the noxious emanations of swamps, and their remedies)" he recognized swamp areas as a breeding ground for malaria and assumed the role of mosquitoes in the disease transmission [1]. In 1897, the English physician Ronald Ross reported in Calcutta, India, his

Corresponding author: Ivan Popivanov, Ph.D., assistant professor, reserch fields: epidemiology of communicable diseases, and preventive medicine. E-mail: drpopivanov@gmail.com. discovery of Anopheles mosquitoes as vectors of disease [2]. Later, in 1900 in Cuba, the American military physician Major Walter Reed confirmed through experiments the transmission of yellow fever via mosquitoes [3, 4]. One of the remarkable discoveries in this field was made by Bacot and Martin in 1914 [5]. They developed a hypothesis about blocked fleas formed in the proventriculus of the infected flea due to enormous multiplication of plague bacilli. Thus, infections generated during subsequent bloodsucking by regurgitation into the bite wound. The figures, showing the obstruction and blood congestion in the flea proventriculus, have not ceased to be included in textbooks for 100 years. Today, this classical description is successfully complemented by multiple lines of scientific evidence for infection, carried out by insects of medical importance, and for pathogens in their particular organs. Such data is 
obtained by microscopic, immunofluorescent, biochemical techniques and other methods, through which the knowledge about the mode of transmission of various infections is becoming objective and specified [6, 7].

For some infections transmitted by live vectors, vaccines have been developed, although the use of such bioproducts is generally limited. Therefore, the control of these infectious diseases is absolutely impossible without effective vector control. Such control is mostly chemical and is based on the achievements of organic chemistry and biochemistry. The knowledge about the biological vectors is important and is provided by medical entomology, medical zoology and medical geography. From a bio-medical point of view, the data on the toxicological effects becomes more relevant. In the context of globalization and the expanding use of chemicals, the importance of environmental principles and criteria increases. With all these scientific methods, the strategy and tactics of the administration and control of the effectiveness of using chemical insecticides are being developed. The control must meet the requirements of two main directions: epidemiological-aiming at maximum limitation or eradication of insects with medical importance, and ecological—ensuring the safety of people, warm-blooded animals and the environment.

\section{History-DDT-era}

The beginning of modern chemical disinsection is associated with boost of the development of organic chemistry, and especially with the discovery of DDT (dichlorodiphenyltrichloroethane). The Swiss chemist Paul Müller discovered DDT's contact-insecticidal action in 1939 (awarded the 1948 Nobel Prize in Medicine), but in practice it was first synthesized in 1873 by Othmar Zeidler in Strasbourg as its insecticidal activity was not suspected for 66 years. The fame of DDT began during World War II (December, 1943). The city of Naples was overcrowded with troops of Allies and refugees.
Against that background, there was a dramatic outbreak of typhus fever with high mortality. The Allied Medical Services applied a DDT-containing powder to treat pediculosis in 673,094 militaries and civilians. Households throughout the city and surrounding villages were also treated systematically. As a result, after February 1944, the number of new patients declined significantly. This was the first example in history, when a major epidemic of typhus (2,020 cases and 429 deaths), spread among troops, population and prisoners, with high pediculosis and poor living conditions, was brought under control in such a short time [8]. The situation of malaria in British Ceylon is another demonstrative example. The application of DDT was launched in 1944 and from 2.8 million cases with 13,000 deaths in 1946, they had been reduced to 7,300 with non-fatal cases in 1963 [9]. The observed anti-epidemic effects of DTT in different parts of the world were numerous and unprecedented. Accelerated implementation in the practice and production of large number of products based on DDT in all possible forms started in many countries. Only in the USA about 675,000 tons were used for 30 years. World production in the early 1970s has reached up to about 400,000 tons annually and the total production so far is estimated to be 1.8 million tons. A significant part (about 80\%) has been applied in agriculture [10, 11]. In Bulgaria, the use of DDT started in 1948.

With the widespread use of DDT and other organochlorine insecticides a qualitative leap in medical disinsection was achieved. The empirical approach of this activity remained in the history. Considering the rapidly achieved excellent results in limiting malaria, leishmaniasis, typhus and yellow fever in the 1940s and 1950s, many researchers compared the importance of organochlorine insecticides for preventive medicine with the importance of using antibiotics in clinical medicine.

However, in the 1960s, sufficient evidence for the serious toxic or adverse environmental effects of DDT was accumulated [12]. Scientists warned the society, 
"the euphoria passed", and the accelerated pace of implementation in the practice were remarkably delayed. In the early 1970s, on the recommendation of WHO, the industrially developed countries suspended its usage. Many other countries followed the ban of DDT, at different times thereafter. The Stockholm convention on persistent organic pollutants (2001) strongly restricted the use of DDT and allowed its use only for vector control of cutaneous leishmaniasis and malaria in countries that are highly endemic [13]. The United Nations Environment Programme (2008) predicted its total phase-out by 2020 . The production in the last years was reduced to about 5,000 tons of active substance per year and only in three countries-China, India and North Korea. Currently, DDT is still used for vector control in several countries in Africa and Asia that are highly endemic for cutaneous leishmaniasis and malaria and for plant protection [14, 15].

The adverse effects of DDT were clarified in detail and led to its ban. They were generally associated with its potential for late effects. Long-term persistence in the environment (half-life more than 10 years), results in a stable inclusion in the food chains, with subsequent build-up (biomagnification) in high concentrations in humans, mammals and birds. The accumulation in adipose tissue and biotransformation into the extremely resistant and toxic breakdown product DDE (dichlorodiphenyldichloroethylene) are other side effects. The concentrations of DDT and DDE in the fat fraction of breast milk are important indicators of health risk. Monitoring data in 28 countries were in broad (values) range: the overall trend in the developed countries showed rapid decrease from about 4,500 ng/g in the 1970s to hardly detectable traces at the end of 20th century [12, 16], but in Poland and Greenland the average concentrations of DDE remained over 6,000 ng/g and over 3,000 ng/g, respectively, in the year 2000 [17]. The prevalence of DDE (with definitely slower elimination from the body compared to DDT) in these countries is a marker for its persistence in the natural food resources, from which it can pass into humans.
The situation in Greenland is explained by the fact that the population consumes predominantly seafood and this reflects the global process of contamination of the oceans in recent decades [10]. The higher concentrations of DDT established in Tanzania (5,500 ng/g), Zimbabwe (4,900 ng/g) and Mexico (4,700 ng/g) are due to the fact that the use was banned recently [18]. Carcinogenicity studies are hampered by methodological limitations and assumptions are based mainly on experimental models [11]. The causality with breast cancer was most widely studied. Some studies suggest a five-fold increased risk in women of childbearing age during the years of peak usage of DDT [19]. There are studies for a causal link with pancreatic cancer, leukemia, diabetes, children's neurological development. Although the data on the cause-effect relationship in these cases are controversial, studies in women and children in some regions raise concern [20].

Another adverse effect of DDT use is resistance development. The first observation was in 1946 for Anopheles mosquitoes, and many other insects were proven subsequently [21].

\section{Contemporary Insecticides}

The arsenal of applied epidemiology nowadays counts mainly on organophosphate insecticides, carbamate insecticides and synthetic pyrethroids. The group of insect growth regulators is in the process of being put into practice.

The group of organophosphate insecticides was initially developed as a new generation chemical weapon (nerve agents) during World War II and subsequently widely used in agriculture. They were used for medical disinsection since the 1950s [22]. Their position as an alternative to the organochlorides was due to some advantages:

- rapid decomposition to non-toxic products;

- considerably shorter half-life and thereby reducing the risk of chronic poisoning and environmental pollution; 
- a well known mode of action (as inhibitors of acetylcholinesterase);

- availability of effective antidote-atropine;

- ability to monitor the staff working with them through periodic control of the enzyme acetylcholinesterase [23].

The growing resistance of insects to organochlorine insecticides was another important reason for the replacement of DDT with organophosphate insecticides.

Carbamate insecticides have biological activity and mode of action similar to organophosphates-they inactivate acetylcholinesterase, but do not undergo metabolism. This difference makes their effect somewhat reversible.

Synthetic pyrethroids were preceded by pyrethrins-natural organic compounds with active substances chrysanthemic acid and pyrethric acid, extracted from the seed cases of some sorts of Chrysanthemum. In China, they were known even B.C. and the commercial usage referred to the 19th century, when in some Middle East, East Asian and Latin American countries plantations for industrial production were created. The difficulties in the standardization of flower extracts, the dependence of yield on climatic conditions and especially the increased demand for insecticides during World War II, without the possibility to be covered with only natural products, made this type of production ineffective. All this pushed scientists to the search of new chemical substances and led to the aforementioned putting of DDT into practice in large-scale.

When the cumulative health and environmental negatives necessitated the elimination of organochlorine insecticides and limitation of the organophosphate insecticides, pyretroids (synthetic analogues of pyrethrins) became dominant. Their insecticidal activity is 10 times more powerful than the natural substances and comes down to blocking the axonal membrane permeability with subsequent excitation of the muscle fibers and paralysis. The selective toxicity is due to a 100 times higher sensitivity of the voltage-gated sodium channels in the nerve structures of insects as compared to the analogous ones in mammals [24]. Furthermore, the insecticidal activity of synthetic pyrethroids is more pronounced at low temperature (the so called "negative temperature effect") [25]. This is associated with the breakdown of the pyrethrin molecule at a high temperature and with its more intensive biodegradation in the microsomes of warm-blooded animals, than in the microsomes of the insects. The insects are poikilotherms and their body temperature is variable and dependent on the ambient temperature. The effect of synthetic pyrethroids is quick and strong ("knock-down effect") and the expenditure of the active substance is more than 10 times lower than the natural derivatives. Their very low oral toxicity to humans, rapid breakdown in the organism and the environment, multipurpose usage (as insecticides and repellents) are important properties, determining the growing levels of use in the world after the 1980s. In the developed countries, they have a share of $70-80 \%$ of all insecticides [26]. Slower trend of increase of their relative share is established in Africa [14].

Neonicotinoids are a class of neuro-active insecticides. They are analogous to natural tobacco alkaloids and developed through chemical synthesis. The class was widely used in the agricultural practice, but did not have a large share in the medical disinsection. The first insecticide formulation from this group for domestic purposes, authorized for use in Bulgaria a few years ago, is now banned along with the entire class. In 2013 Bulgaria joined the EU Commission restrictions of use of neonicotinoids [27], which were suspected to be a contributing factor of bee colony collapse disorder.

\section{New Technologies}

One of the directions for improvement is targeting immature forms of insects. For that purpose biological insecticides were used for a long time (e.g., Bacillus 
thuringiensis), and after the 1960s, some organophosphate insecticides were used. New and perspective agents in this field are IGRs (insect growth regulators), meeting the increased environmental requirements and extremely unlikely to cause acute poisoning in humans and animals. They affect insect structures that are not typical for humans. The mode of activity of IGRs is larvicidal by interfering with chitin metabolism and thus preventing the insect from reaching maturity. The chemical substances were known since 1960s. At the end of 1970s plant protection products were registered and products for medical disinsection were developed after the year 2000. The main substances are diflubenzuron (chitin synthesis inhibitor) and novaluron (synthetic analogue of the juvenile hormone). IGRs treated larvae cannot release the old chitin exoskeleton, or the new one is fragile and thus they don't have a normal exoskeleton. If IGRs are applied on larvae in the last phase of development, the pupae or imagoes become underdeveloped and deformed. The result is death at the stage of metamorphosis or shortly thereafter. If transformed to imago forms (e.g., mosquito), they have visible abnormalities and cannot fly out due to deformed wings or fragile limbs. IGRs can also have an effect on the eggs, causing sterility [28]. These effects are due to blocking of the membrane transport of chitin precursors [29] which occurs after affecting the expression of multiple genes involved in the chitin metabolism [30]. Diflubenzuron has low levels of oral toxicity $-4,640 \mathrm{mg} / \mathrm{kg}$, and has extremely low toxicity to mammals and fish, accordingly. Recent results from a study on an insecticide product with diflubenzuron-granular formulation in mosquito habitat in Bulgaria ascertained progressively increasing number of killed larvae and after the 4th day all larval forms were non-viable [31]. In other studies on the effect of granules and water-soluble powder with an active substance diflubenzuronon mosquito populations in large natural ponds in the Mediterranean and some other regions of the world, complete loss of viability of larvae was established between 6th and 12th days after treatment [32]. This was due to the fact that the dilution of insecticide formulation was more pronounced, and the density of the mosquito population was significantly higher.

Nanotechnologies are another contemporary field of pest control. They are used to improve the conventional /classical chemical insecticides. The recently developed nanosuspensions and nanoemulsions are new, more effective forms of some of the so far implemented chemical insecticides [33]. They are used to achieve higher efficiency, because the nanoparticles penetrate more easily through the ion channels [34-36]. Thus, reduction of the concentration and amount of the insecticide substance is achieved.

\section{Vector Control: Present State from Medical and Environmental Perspective. Implementation Strategies}

The overall global environmental assessment of the situation concerning chemical insecticides now is the following: the burden of people and environment with DDT is progressively decreasing and the trend of clearing up the nature from some other organochlorides, from organophosphate and carbamate insecticides is slow. Synthetic pyrethroids are the most promising, but their importance should not be overemphasized. Their incorporation as a primary means in the mosquito control programs in South Africa in 1996 did not bring the desired results. Moreover, because of their short biocidal effect and resistance development in mosquitoes, in some places the growth of anopheles mosquitoes' population was ascertained (particularly Anopheles funestus). This necessitated a revision of the regulations on the use of DDT. Now DDT is authorized for use in several countries, with application only on the inside walls of homes (indoor residual spraying-IRS), and with a total ban on treatment of body, clothing or bedding. Concerning the class of insect growth regulators, it is assumed that they have a great potential to reduce the overall environmental risk 
from insecticides. Nanotechnologies are in the early stages of use. Studies on their side effects are forthcoming, in view of their high penetration through membrane ion channels that could create risks for humans and animals [37, 38].

The selection of insecticide formulations is complied with the specific circumstances and characteristics of the active substance. During the treatment of objects, affected by the floods in Bulgaria in 2005, the specialized units of Military Medical Academy used insecticide formulations with an active substance malation for open areas and synthetic pyrethroids for indoor application [39]. According to the NATO standardization agreements, the insecticides for individual protection are on synthetic pyrethroid base [40]. The phthalic compounds, recently recommended as the most suitable for repelling insects, already are replaced by the synthetic pyrethroids. Carbamate insecticides have a better effect on crawling insects. The insect control strategy provides treatments early in the spring with IGRs to suppress the formation of initial population, followed by periodical treatments to maintain a safe level. Pyrethroids and other insecticides in this case are supplemental to treatment. When mass reproduction of insects is established, treatments with synthetic pyrethroids are recommended to limit the number of imago forms and then proceeding to use of IGRs (e.g., diflubenzuron).

The optimal combination of larvicides and insecticides for imago forms in medical disinsection can reduce aggressive to humans and animals organophosphate and carbamate insecticides.

\section{Conclusions}

In the 85 years history of chemical insecticides use for vector control two stages are outlined. In the initial stage the main purpose was to respond only to the need for management of severe epidemic situations. Currently, serious issues concerning the ecotoxicology of chemical insecticides are raised. The improvement of chemical insecticides through new concepts and technologies is a fact. In this context, the group of synthetic pyrethroids has a great potential and the IGRs are approaching the concept of the "ideal insecticide".

Considering that chemical insecticides are used in agriculture and veterinary medicine, even in much higher concentrations and quantities, achievement of adequate interaction and coordination within these scientific and applied fields is essential for effective control of public health.

\section{References}

[1] Mikov, O. 2005. "History of the Studies on Malaria Mosquitoes in Bulgaria (Istoria na prouchvaniata vurhu malarijnite komari v Bulgaria).” Infectology 4: 39-47. (in Bulgarian)

[2] Ross, R. 1897. "On Some Peculiar Pigmented Cell Found in Two Mosquitoes Fed on Malarial Blood.” Br. Med. J. 2 (1929): 1786-8.

[3] Mehra, A. 2009. "Politics of Participation: Walter Reed's Yellow-Fever Experiments.” Virtual Mentor 11 (4): 326-30.

[4] Gillett, M. C. 1995. "Public Health in Cuba.” In The Army Medical Department 1865-1917 (Army Historical Series), edited by Clarke J. J. Washington, DC: Center of Military History, U.S. Army, 229-56.

[5] Bacot, A. W., and Martin, C. J. 1914. "Observations on the Mechanism of the Transmission of Plague by Fleas.” $J$. Hyg. 13 (Suppl.): 423-39.

[6] Eisen, R. J., and Gage, K. L. 2012. "Transmission of Flea-Borne Zoonotic Agents.” Annu. Rev. Entomol. 57: 61-82.

[7] Mani, R. J., Reichard, M. V., Morton, R. J., Kocan, K. M., and Clinkenbeard, K. D. 2012. "Biology of Francisella Tularensis Subspecies Holarctica Live Vaccine Strain in the Tick Vector Dermacentor Variabilis.” Plos One. http://www.plosone.org/article/info\%3Adoi\%2F10.1371 \%2Fjournal.pone.0035441.

[8] Soper, F. L., Davis, W. A., Markham, F. S., and Riehl, L. A. 1947. "Typhus Fever in Italy, 1943-1945, and Its Control with Louse Powder.” Am. J. Hyg. 45 (3): 305-30.

[9] Harrison, G. A. 1978. Mosquitoes, Malaria and Man: A History of the Hostilities Since 1880. New York: Dutton.

[10] Geisz, H. N., Dickhut, R. M., Cochran, M. A., Fraser, W. R., and Ducklow, H. W. 2008. "Melting Glaciers: A Probable Source of DDT to the Antarctic Marine Ecosystem.” Environ Sci Technol. 42 (11): 3958-62.

[11] Turusov, V., Rakitsky, V, and Tomatis, L. 2002. "Dichlorodiphenyltrichloroethane (DDT): Ubiquity, Persistence, and Risks.” Environ Health Perspect. 110 (2): 
125-8.

[12] Smith, D. 1999. "Worldwide Trends in DDT Levels in Human Milk.” Int. J. Epidemiol. 28: 179-88.

[13] Stockholm Convention on Persistent Organic Pollutants. http://www.pops.int/documents/convtext/convtext_en.pdf

[14] Van Den Berg, H. 2009. "Global Status of DDT and Its Alternatives for Use in Vector Control to Prevent Disease." Environ Health Perspect. 117 (11): 1656-63.

[15] World Health Organization, 2011. Global Malaria Programme. The Use of DDT in Malaria Vector Control. WHO Position Statement (revised). Geneva, WHO.

[16] Norén, K., and Meironyté, D. 2000. "Certain Organochlorine and Organobromine Contaminants in Swedish Human Milk in Perspective of Past 20-30 Years.” Chemosphere 40: 1111-23.

[17] Jaga, K., and Dharmani, C. 2003. "Global Surveillance of DDT and DDE Levels in Human Tissues.” Int. J. Occup. Med. Environ Health 16 (1): 7-20.

[18] Natural Resources Defense Council. 2005. "Healthy Milk, Healthy Baby. Chemical Pollution and Mother's Milk.” Natural Resources Defense Council. Accessed March 25, 2005. http://www.nrdc.org/breastmilk/ddt.asp\#note15.

[19] Cohn, B. A., Wolff, M. S., Cirillo, P. M., and Sholtz, R. I. 2007. "DDT and Breast Cancer in Young Women: New Data on the Significance of Age at Exposure." Environ. Health Perspect. 115 (10): 1406-14.

[20] Cohn, B. A., Cirillo, P. M., Wolff, M. S., Schwingl, P. J., Cohen, R. D., Sholtz, R. I., Ferrara, A., Christianson, R. E., van den Berg, B. J., and Siiteri, P. K. 2003. "DDT and DDE Exposure in Mothers and Time to Pregnancy in Daughters.” Lancet. 361 (9376): 2205-6.

[21] McGinn, A. P. 2002. "Malaria, Mosquitoes, and DDT." World watch magazine. May/June 2002; 15 (3). http://www.worldwatch.org/node/517.

[22] Taylor, W. J., Kalow, W., and Sellers, E. A. 1965. "Poisoning with Organophosphorus Insecticides." Can Med. Assoc. J. 93 (18): 966-70.

[23] Fukuto, T. R. 1990. "Mechanism of Action of Organophosphorus and Carbamate Insecticides.” Environ. Health Perspect. 87: 245-54.

[24] Wakeling, E. N., Neal, A. P., and Atchison, W. D. 2012. Pyrethroids and Their Effects on Ion Channels. In: Pesticides-Advances in Chemical and Botanical Pesticides, edited by R.P. Soundararajan, Rijeka, Croatia: InTech, 40-66.

[25] Gubev, E. 1973. Disinfection, Disinsection and Deratization Textbook (Dezinfekcia, dezinsekcia I deratizacia). Sofia, Bulgaria, 221-223. (in Bulgarian)

[26] Spurlock, F., and Lee, M. 2008. Synthetic Pyrethroid Use Patterns, Properties and Environmental Effects. In Synthetic Pyrethroids. Occurrence and Behavior in Aquatic Environments, edited by Gan, J., Spurlock, F.,
Hendley, P., and Weston, D. P., ACS Symposium Series. Washington, DC: American Chemical Society Copyright Office\&Publications Division, 3-25.

[27] EU Commission Implementing Regulation No 485/2013 Amending Implementing Regulation (EU) No 540/2011, as regards the Conditions of Approval of the Active Aubstances Clothianidin, Thiamethoxam and Imidacloprid, and Prohibiting the Use and Sale of Seeds Treated with Plant Protection Products Containing those Active Substances. Official Journal of the European Union, L 139/26; 25 May 2013.

[28] Belinato, T. A., Martins, A. J., Lima, J. B., Lima-Camara, T. N., Peixoto, A. A., and Valle, D. 2009. "Effect of the Chitin Synthesis Inhibitor Triflumuron on the Development, Viability and Reproduction of Aedes aegypti.” Mem. Inst. Oswaldo. Cruz. 104 (1): 43-7.

[29] Turnbull, I. F., and Howells, A. J. 1983. "Integumental Chitin Synthase Activity in Cell-free Extracts of Larvae of the Australian Sheep Blowfly, Lucilia cuprina, and Two Other Species of Diptera." Austr. J. Biol. Sci. 36 (3): 251-62.

[30] Kumari, M. 2010. "Mode of Action of the Insect Growth Regulator Diflubenzuron: A Comprehensive Study in Tribolium Castaneum Utilizing Genomic Tiling Array and Immunolocalization Approaches.” Presented at ESA 58th Annual Meeting, San-Diego, USA. http://esa.confex.com/esa/2010/ webprogram/Paper51596.

[31] Shalamanov, D., Popivanov, I., Tzvetanov, Tz., and Atanasov, Hr. 2010. Medical disinsection: development and contemporary ecological aspects [Medicinska dezinsekcia - razvitie I savremenni ekologichni aspekti] In Proceedings of Jubilee Scientific Conference with International Participation Public Health in the 21st Century-Realities and Perspectives, edited by Grancharova, G. Pleven. Publishing centre of MU-Pleven, 1: 267-70. (in Bulgarian)

[32] E.I.D.-Nuisance Mosquito Control in Natural Mediterranean Areas: Methodological Proposal for the Sustained Management of a Ramsar Site in Languedoc-Roussillon (project). EU Environment Life Programme LIFE99ENV/F/000489. http://ec.europa.eu/environment/life/project/Projects/inde x.cfm?fuseaction=search.dspPage\&n_proj_id=1446\&doc Type=pdf.

[33] Sasson, Y., Levy-Ruso, G., Toledano, O., and Ishaaya Is. 2007. "Nanosuspensions: Emerging Novel Agrochemical Formulations.” In Insecticides Design Using Advanced Technologies, edited by Ishaaya, Is., Horowitz, A. R., Nauen, R. Springer Berlin Heidelberg, 1-39.

[34] Perlatti, B, de Souza Bergo, P. L., das Graças Fernandes da Silva, M. F., Fernandes, J. B., and Forim, M. R. 
"Polymeric Nanoparticle-Based Insecticides: A Controlled Release Purpose for Agrochemicals. In Insecticides-Development of Safer and More Effective Technologies, edited by Trdan, S. Rijeka, Croatia: InTech, 23-50.

[35] Bhattacharyya, A., Bhaumik, A., Rani, P. U., Mandal, S., and Epidi, T. T. 2010 "Nano-particles-A Recent Approach to Insect Pest Control.” Afr. J. Biotechnol. 9 (24): 3489-93.

[36] Mondal, N. K., Chowdhury, A., Dey, U., Mukhopadhya, P., Chatterjee, S., Das, K., and Datta, J. K. 2014. “Green Synthesis of Silver Nanoparticles and Its Application for Mosquito Control.” Asian Pac. J. Trop. Dis. 4 (Suppl. 1): S204-10.

[37] Barry, B. E. 2008. "The State of the Science-Human Health, Toxicology and Nanotechnological Risk.” In
Nanotechnology — Health and Environmental Risks, edited by Shatkin J. A. UK: CRC Press Taylor \& Francis Group, 63-76.

[38] Hoet, P. H. M., Brüske-Hohlfeld, I., and Salata, O. V. 2004. "Nanoparticles-Known and Unknown Health Risks.” J. $\quad$ Nanobiotech. $\quad 2$ : 12. http://www.jnanobiotechnology.com/ content/2/1/12.

[39] Tzvetanov, Tz., Popivanov, I., Shalamanov, D., and Mladenov, K. 2006. “Contemporary Aspects in Carrying out Disinsection and Deratization in Disaster Situations (Savremenni postanovki v provezhdaneto na dezinsekciata I deratizaciata pri bedstveni situacii).” Bulletin DDD 1-4: 57-67. (in Bulgarian)

[40] STANAG 2048. Deployment Pest and Vector Surveillance and Control-AMedP-4.2. 4th ed., NATO Standardization Agency, Brussels, Belgium, 2014. 